\title{
Melanin Production by Xanthomonas campestris pv. vesicatoria under the Effect of Aromatic Oil's Vapour Phase - A New Report
}

\author{
Kadam NA*, Raghuwanshi KS and Borkar SG \\ Department of Plant Pathology and Microbiology, Post Graduate Institute, Mahatma Phule \\ Krishi Vidyapeeth, Rahuri, Maharashtra, India
}

\begin{abstract}
*Corresponding author: Nivedita A Kadam, Department of Plant Pathology and Microbiology, Post Graduate Institute, Mahatma Phule Krishi Vidyapeeth, Rahuri, Maharashtra, India, Email: nivedita024@gmail.com
\end{abstract}

\section{Research Article \\ Volume 4 Issue 8}

Received Date: December 17, 2020

Published Date: December 31, 2020

DOI: $10.23880 /$ jenr-16000225

\section{Abstract}

In the present study, we evaluated the effect of aromatic oil's vapour phase (aroma) on the melanin production in plant pathogenic bacteria Xanthomonas campestris pv. vesicatoria $(\mathrm{Xcv})$, the causal agent of bacterial blight of tomato. Species of the genus Xanthomonas typically produce yellow xanthomonadin pigment, but here in the presence of aromatic oil's vapour phase the bacterium produced a melanin-like pigment. Among the 10 commercially available synthetic aromatic oils tested, $X c v$ produced yellow colonies with dark brown extracellular melanin-like pigment in Nutrient Agar media, in the presence of vapour phase of dhavana (Artemisia pallens), henna (Lawsonia inermis), kasturi (Musk of deer), firdous (Combination of Jasminum officinale, Cinnamomum verum, and Nelumbo nucifera), and rose (Rosa damascena) aromatic oils. Firdous and rose aromatic oil treatments were further used to produce pigment in Nutrient broth, which yielded $4.61 \pm 0.07 \mathrm{and} 5.13 \pm 0.08 \mathrm{mg}$ / $\mathrm{ml}$ pigment, respectively. After extraction and purification of the pigment, its characterization was carried out by employing the analytical techniques like Ultraviolet-Visible (UV-Vis) spectrophotometer and Fourier Transmission Infra-red (FTIR) Spectrometer, and the pigment was confirmed as melanin. Till date, melanin pigment has been reported in algae, bacteria, fungus, lichen, and mushroom, but it has not been reported in plant pathogenic bacteria particularly Xcv and therefore this is the first report. Also, the report of aromatic oil's vapour phase mediated melanin production in bacteria is novel and can be further explored to identify high melanin yielding microbe, owing to the increasing demand for melanin in the market and its versatile applications.

Keywords: Xanthomonas campestris pv. vesicatoria (Xcv); Melanin Pigment; Aromatic Oils Vapour Phase

\section{Introduction}

We are all familiar with the role of melanin pigment in imparting colour to human skin and hair. They are ubiquitous in nature, found in all living organisms from microbes to plants and animals. These pigments are produced by the oxidative process known as melanogenesis by polymerization of phenolic compounds, where L-tyrosine or L-DOPA [1] or catechol [2] or HGA [3,4] are used as the precursors. Melanin obtained from microbes varies in colour viz. yellow, red, brown and black, and based on these they are classified as eumelanin, pheomelanin, and allomelanin $[5,6]$. Nowadays, production and extraction of melanin from microorganisms is of great interest, owing to its versatile applications. Melanin offers multiple antibiotic resistance [7], UV protection [8,9], exhibit significant antibacterial $[10,11]$, antifungal $[10]$, antioxidant activity $[10,11]$ along with anticancer potential $[10,12]$. It enhances the survival 
and competitive abilities of organisms in harsh conditions $[13,14]$. The organism producing melanin can be used for heavy metal remediation, where melanin is involved in absorption and accumulation of the heavy metals within the tissue [15]. It has been used as a reducing and stabilizing agent for the synthesis of silver and gold nanostructures [16]. It has the metal binding capacity [9], and is used in the fabrication of radio-protective materials, food packaging, cosmetics, and in medicine [6]. Apart from this, melanin nanoparticles also have strong antibacterial activity [11] and are used in heavy metal absorption [17]. Owing to the increasing demand for melanin in the market and its versatile applications, economically feasible methods of melanin production from microorganisms should be identified.

Aromatic oils are extracted from plants, they have the characteristic fragrance of the plant and contain specific volatile compounds. These aromatic/essential oils are extensively used in perfumes, incense, cosmetics, fresheners and cleaning products like soaps and detergents, and to add flavor in food and beverages. They are reported to have antifungal [18], antibacterial $[19,20]$ and insect repellent ability [21], and thus have been proved to be a potential alternative to synthetic chemicals used presently. Apart from this, they are also reported to be used in aromatherapy in human beings, either by inhalation or by applying it to the affected body part after dilution of the oil [22]. However, use of aromatic oils in the production of pigments in microbes is unknown, and therefore studied in the present experimentation by using Xanthomonas campestris pv. vesicatoria (Xcv), plant pathogenic bacteria causing bacterial blight disease in tomato (Lycopersicon esculentum Mill.) and pepper (Capsicum annum L.). Species of the genus Xanthomonas typically produce yellow pigment xanthomonadin except Xanthomonas campestris pv. phaseoli which produce melanin-like pigment [4]. In the present study, the effect of aromatic oils vapour phase (aroma) was observed in the production of melanin pigment in the plant pathogenic bacteria $X c v$.

\section{Materials and Methods}

\section{Isolation of Plant Pathogenic Bacteria Xanthomonas campestris pv. vesicatoria (Xcv)}

To obtain the bacterial culture of $X c v$, the leaves samples of tomato exhibiting typical leaf spot symptoms of XcV i.e. water soaked lesions on the leaf, were collected. The bacterial pathogen Xcv was isolated on Nutrient Agar (NA) media by employing streak plate method, a routine isolation technique of bacterial plant pathogens [23]. The pure culture of the bacterium was obtained, maintained, and used in the present study.

\section{Effect of Different Aromatic Oil's Vapour Phase (Aroma) on Pigment Production in Xcv}

Effect of different aromatic oil's vapour phase (aroma) on pigment production in $X c v$ was determined by employing a simple cotton swab method, where cotton swab was used instead of disc in the disc volatilization method [20]. Briefly, a simple cotton swab technique was developed in our laboratory to test the efficacy of the vapour phase of aromatic oils on the bacterial pathogen in Petri plates. For this, the bacterial culture was streaked on the sterilized Nutrient Agar Petri plates, $100 \mu \mathrm{l}$ of aromatic oil was added on the small piece of sterile cotton swab (of $0.5 \mathrm{~cm}$ diameter, $20 \mathrm{mg}$ weight) and this cotton swab was then sticked on the inner surface of upper lid of the Petri plate, so that the cotton swab remains in inverted position on the bacteria streaked on the media plate. These Petri plates were sealed with parafilm tape to trap the vapour phase of aromatic oils inside the plate. In all 10 commercially available synthetic aromatic oils were tested (Table 1).

\begin{tabular}{|c|c|}
\hline Sr. No. & List of aromatic oils \\
\hline 1 & Dhawana (Artemisia pallens) \\
\hline 2 & Heena (Lawsonia inermis) \\
\hline 3 & Kewda (Pandanus odorifer) \\
\hline 4 & Khus (Chrysopogon zizanioides) \\
\hline 5 & $\begin{array}{c}\text { Firdous (Combination of Jasminum officina- } \\
\text { le, Cinnamomum verum, Nelumbo nucifera) }\end{array}$ \\
\hline 6 & Nilgiri (Eucalyptus globulus) \\
\hline 7 & Sandalwood (Santalum album) \\
\hline 8 & Kasturi (Musk of deer) \\
\hline 9 & Citronella (Cymbopogon nardus) \\
\hline 10 & Rose (Rosa damascena) \\
\hline
\end{tabular}

Table 1: List of aromatic oils.

\section{Extraction and Purification of Melanin -Like Pigment}

Extraction and purification of melanin was carried out according to the protocol used by Tarangini and Mishra [9] with slight modifications. Three sets of $250 \mathrm{ml}$ of Nutrient broth were prepared and inoculated with $X c v$. Two of the conical flasks inoculated with $X c v$ were plugged with the sterilized cotton plugs and on the surface of these cotton plugs, facing inside the conical flask $1 \mathrm{ml}$ of firdous and rose aromatic oil was added, respectively. The cotton plug and beak of conical flask were covered with parafilm tape in order to trap the vapour phase of aromatic oils inside the flask. The third conical flask was inoculated with $X c v$ and 
was then plugged with simple sterilized cotton plug without any aromatic oil, and this flask was maintained as control. The flasks were kept on rotary shaker with $120 \mathrm{rpm}$ at 28 $\pm 2{ }^{\circ} \mathrm{C}$ temperature and the bacteria was allowed to grow in Nutrient broth for 4 weeks till dark brown pigment was produced in aromatic oil treated flasks.

After the growth of bacteria for 4 weeks and production of dark brown pigment in Nutrient broth, the broth was centrifuged at $6000 \mathrm{rpm}$ for $15 \mathrm{~min}$ to separate the cell mass. The supernatant was collected and kept aside. The pellet i.e. the cell mass was removed and suspended in distilled water. Then it was again centrifuged at $6000 \mathrm{rpm}$ for 15 min to collect the supernatant. The overall supernatant was collected and acidified using $1 \mathrm{~N} \mathrm{HCl}$ to $\mathrm{pH} 2$ to precipitate the pigment. This precipitate was harvested by centrifugation at $10000 \mathrm{rpm}$ for 10 mins. The precipitate thus obtained was washed with ethanol three times, dried overnight and stored for further studies. The experiment was repeated three times and the quantity of pigment produced was measured, the mean and standard deviation were also calculated for the quantity of pigment.

\section{Chemical Characterization of the Pigment}

Chemical tests were carried out to analyse the characters of the pigment and the results were compared with the characters of melanin pigment. The solubility of the purified black pigment was tested in distilled water. The solubility of the pigment was also checked in organic solvents like ethanol, chloroform, and acetone and alkaline solutions viz.
$1 \mathrm{~N} \mathrm{NaOH}$ and $1 \mathrm{~N} \mathrm{KOH}$. The reaction of the pigment with an oxidizing agent such as $30 \% \mathrm{H}_{2} \mathrm{O}_{2}$ and strong acid like1 $\mathrm{N}$ $\mathrm{HCl}$ was also determined $[1,10,16]$.

\section{Ultraviolet-Visile (UV-Vis) and Fourier Transmission Infra-Red (FTIR) Spectroscopy}

The pigment was examined at $200 \mathrm{~nm}$ to $900 \mathrm{~nm}$ wavelengths using the UV-Vis spectrophotometer to prepare the graph using its absorbance value $[1,10,16]$. The FTIR Spectroscopy of the pigment was carried out by first mixing the purified black pigment with IR grade $\mathrm{KBr}$ (1:10), and then it was pressed into disks under high pressure $[1,10,16]$. The FTIR spectrum was recorded at 4,000-600 $\mathrm{cm}^{-1}$ using the FTIR spectrometer. The UV-Vis and FTIR spectroscopy results thus obtained were compared to the previous reports for melanin, based on the absorbance peaks.

\section{Results}

\section{Effect of Different Aromatic Oil's Vapour Phase on Pigment Production in $\mathrm{XcV}$}

XCV produced yellow coloured colonies with brown extracellular pigmentation under the effect of aromatic oil's vapour phase (aroma) of dhavana, henna, kasturi, firdous and rose treatments (Figure 1). Dark brown extracellular pigment was observed in firdous and rose treatments while light brown extracellular pigment was seen in dhavana, henna and kasturi treatments. In the rest of the aromatic oil treatments normal yellow coloured colonies were formed.

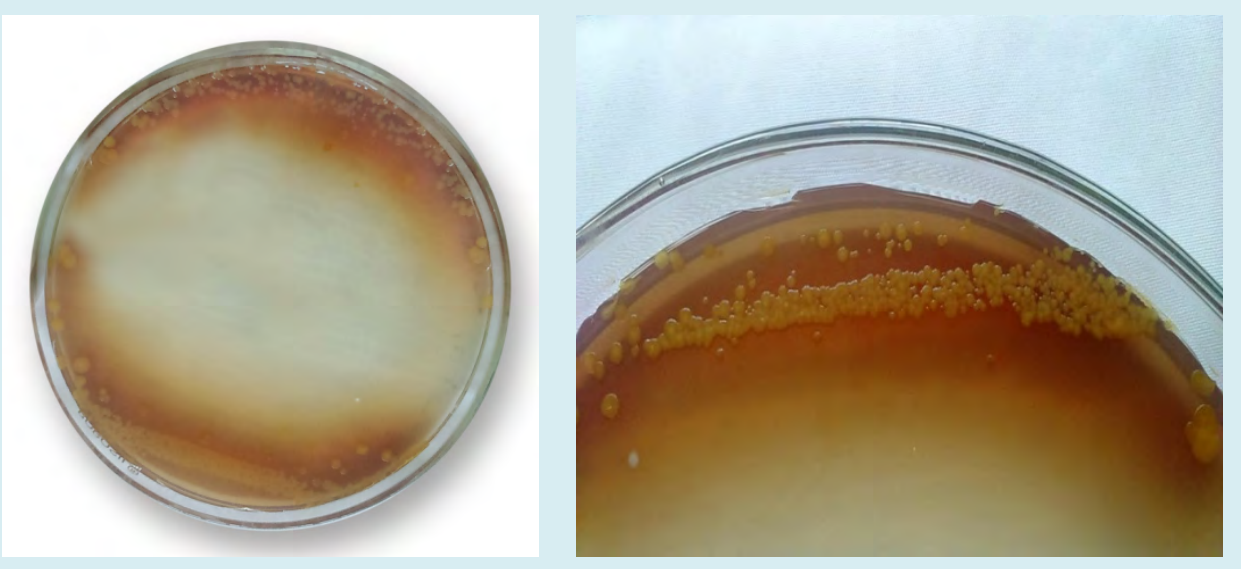

Figure 1: Extracellular dark brown pigment produced by Xanthomonas campestris pv. vesicatoria in Nutrient Agar plates under the effect of aromatic oil's vapour phase (aroma).

\section{Quantification of Extracted and Purified Pigment}

The Nutrient broth inoculated with $X c v$ and treated with firdous and rose aromatic oil's vapour phase treatment, became dark brown coloured after 4 weeks (Figure 2); whereas the Nutrient broth of control flask inoculated with $X c v$ turned yellow coloured. The dark brown colour of the Nutrient broth was due to extracellular pigmentation in the broth. This pigment in the Nutrient broth was extracted, 
Journal of Ecology and Natural Resources

purified and black colour pellet was obtained. The quantity of pigment produced in the flasks treated with firdous and rose aromatic oil's vapour phase was $4.61 \pm 0.07$ and 5.13 $\pm 0.08 \mathrm{mg} / \mathrm{ml}$, respectively.

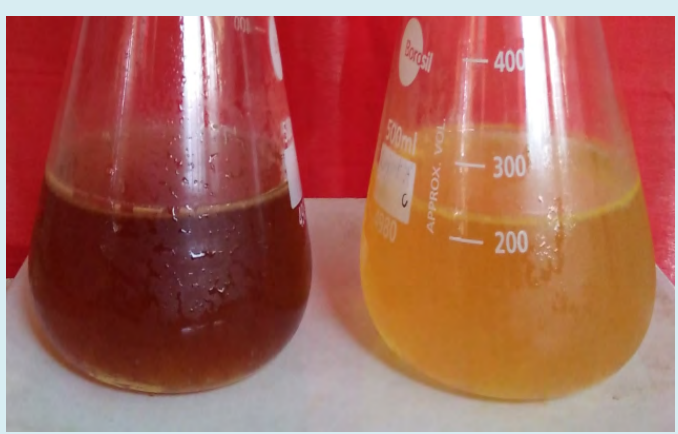

Figure 2: Extracellular dark brown and yellow pigmentation produced by Xanthomonas campestris pv. vesicatoria in Nutrient broth flasks under the effect of aromatic oil's vapour phase and control, respectively.

\section{Chemical Characterization of the Pigment}

The pigment was insoluble in water and organic solvents viz. ethanol, chloroform, and acetone, but was soluble in alkaline solution of $1 \mathrm{~N} \mathrm{NaOH}$ and $1 \mathrm{~N} \mathrm{KOH}$. The pigment decolourized when treated with oxidizing agent $\mathrm{H}_{2} \mathrm{O}_{2}$, while readily precipitated with $\mathrm{HCl}$ producing black colored precipitation.

\section{UV-Vis Spectroscopy}

When the UV-Vis spectroscopy of extracellular pigment produced by $X c v$ was studied at $200 \mathrm{~nm}$ to $900 \mathrm{~nm}$ wavelength range, higher absorption peak was observed between 250 $\mathrm{nm}$ to $350 \mathrm{~nm}$ wavelength i.e. in the UV region. While in the visible region the absorbance spectrum gradually decreased as the wavelength increased. The UV-Vis spectrum was similar for melanin produced under the effect of firdous and rose aromatic oil's vapour phase (Figure 3).

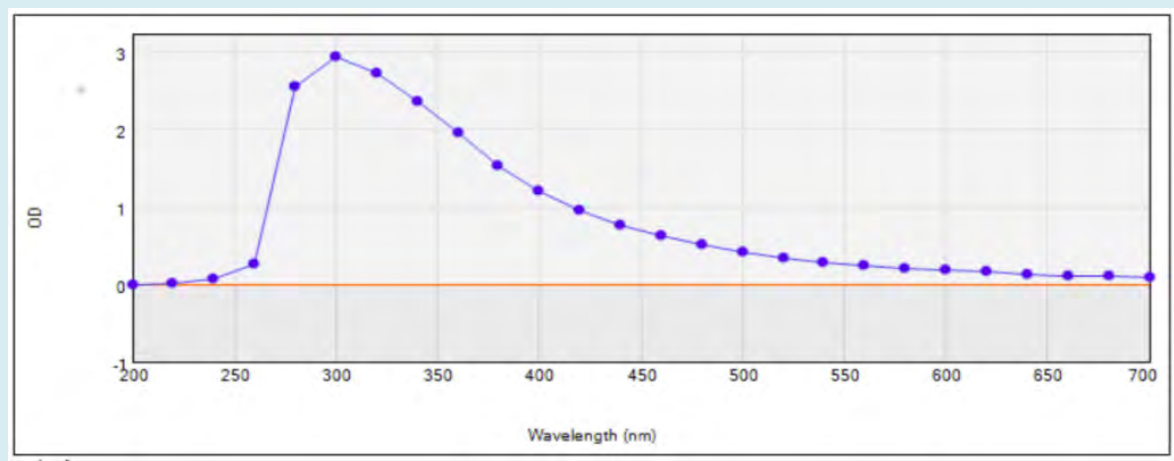

(a)

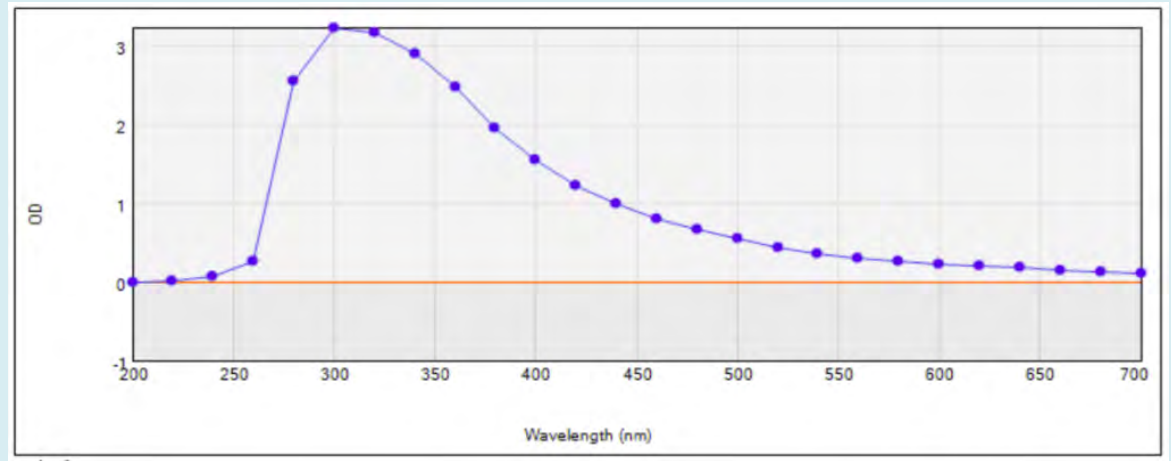

(b)

Figure 3: UV-Visible spectrum of the extracellular pigment produced by Xanthomonas campestris pv. vesicatoria under the effect of firdous (a) and rose (b) aromatic oil's vapour phase showing higher absorption in the ultraviolet region (between 250 $\mathrm{nm}$ to $350 \mathrm{~nm}$ ) which gradually decreased towards visible light. 


\section{FTIR Spectroscopy}

FTIR analysis showed the presence of a broad absorption at $3274.91 \mathrm{~cm}^{-1}$ (firdous) and $3277.87 \mathrm{~cm}^{-1}$ (rose) which represents the presence of hydroxy $(-\mathrm{OH})$ group with amino (-NH) group (Figure 4). The other strong peak obtained at $2931.93 \mathrm{~cm}^{-1}$ (firdous) and $2927.73 \mathrm{~cm}^{-1}$ (rose) attribute to alkyl (-CH) group, whereas the peak at $1623.41 \mathrm{~cm}^{-1}$ (firdous) and $1621.99 \mathrm{~cm}^{-1}$ (rose) may be attributed to aromatic group
$\mathrm{C}=\mathrm{C}$ of amide I and/or of amide II group, or $\mathrm{C}=\mathrm{O}$ or of COOgroup [11]. The peak of N-H at $1517.91 \mathrm{~cm}^{-1}$ (firdous) and $1520.72 \mathrm{~cm}^{-1}$ (rose) shows the presence of a typical indole structure of melanin. The characteristic peak at 1458.94 $\mathrm{cm}^{-1}$ (firdous) and $1454.88 \mathrm{~cm}^{-1}$ (rose) is attributed to $\mathrm{CH}_{2}-$ $\mathrm{CH}_{3}$ bending and is an identity of melanin pigment. The peak at $1211.06 \mathrm{~cm}^{-1}$ (firdous) and $1229.75 \mathrm{~cm}^{-1}$ (rose) may be due to Phenolic $\mathrm{COH}$ stretching of phenolic compounds or anhydride group (C-0) [12].

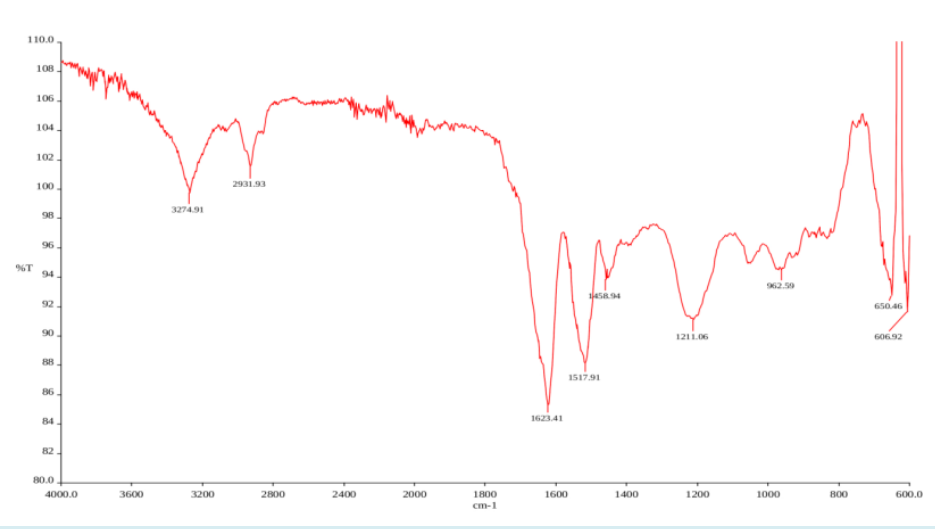

(a)

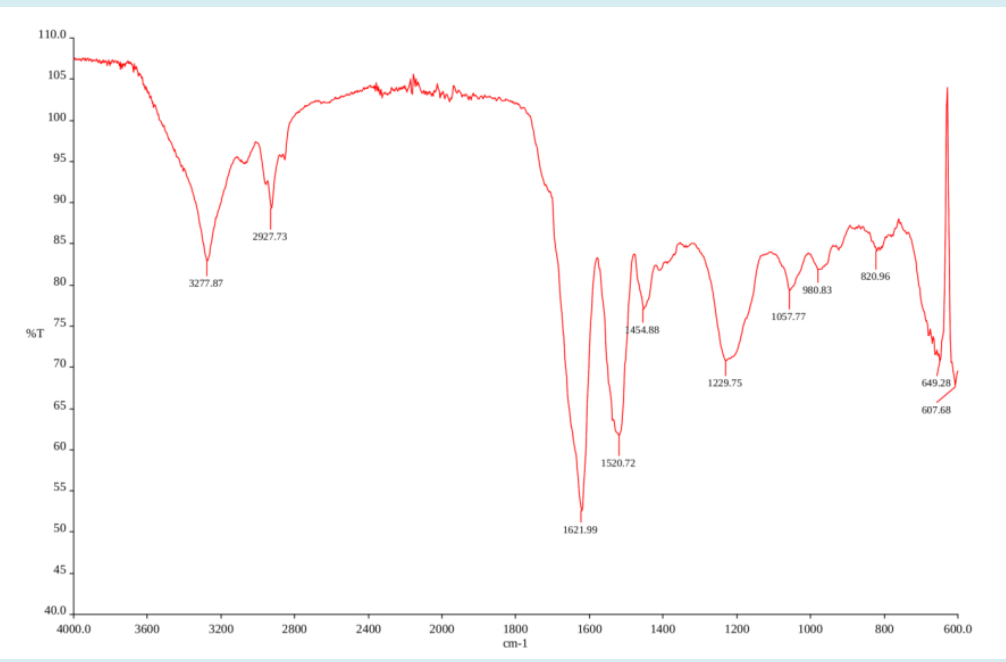

(b)

Figure 4: FTIR spectrum of the extracellular pigment produced by Xanthomonas campestris pv. vesicatoria under the effect of firdous (a) and rose (b) aromatic oil's vapour phase showing a broad absorption spectra at $3274.91 \mathrm{~cm}^{-1}$ (firdous) and 3277.87 $\mathrm{cm}^{-1}$ (rose) which represents the presence of hydroxy $(-\mathrm{OH})$ group with amino $(-\mathrm{NH})$ group and other strong peak obtained at $2931.93 \mathrm{~cm}^{-1}$ (firdous) and $2927.73 \mathrm{~cm}^{-1}$ (rose) attribute to alkyl (-CH) group. Whereas the peak at $1623.41 \mathrm{~cm}^{-1}$ (firdous) and $1621.99 \mathrm{~cm}^{-1}$ (rose) relates to aromatic group (C=C) of amide I and/or of amide II group.

\section{Discussion}

The colonies of Xanthomonas spp. usually produces yellow pigmentation in the growth medium, which is a typical characteristic of the genus. However, due to the effect of vapour phase (aroma) of aromatic oils viz. of dhavana, henna, kasturi, firdous and rose, Xcv produced extracellular dark brown pigmentation in growth media, similar to 


\section{Journal of Ecology and Natural Resources}

melanin. Generally, melanin's are insoluble in water and organic solvent, but they are soluble in alkaline solution. They are oxidized by $\mathrm{H}_{2} \mathrm{O}_{2}$ and are readily precipitated by $\mathrm{HCl}$. Similar results were obtained for the extracellular pigment produced by $X c v$, and the chemical characteristics of the pigment are in agreement with the previous reports $[1,10,16]$. In the UV-Vis spectrum at $200 \mathrm{~nm}$ to $900 \mathrm{~nm}$ wavelength range, the extracellular pigment produced by XcV (Figure 3), shown higher absorption in the ultraviolet region (between $250 \mathrm{~nm}$ to $350 \mathrm{~nm}$ ), and it progressively declined towards visible light, which is a peculiar character of melanin pigment. The UV-Vis spectrum of Xcv pigment was similar to the previous reports of UV-Vis spectrum of melanin pigment $[1,10,16]$. In FTIR spectroscopy, the melanin isolated from Pseudomonas sp. showed similar absorption peaks at 3273 $\mathrm{cm}^{-1}, 2929 \mathrm{~cm}^{-1}$, and $1625 \mathrm{~cm}^{-1}$ [11]. In addition to these peaks, some other peaks were observed at $1539.25 \mathrm{~cm}^{-1}$ corresponding to $\mathrm{N}-\mathrm{H}$ bending; $1423.51 \mathrm{~cm}^{-1}$ showing characteristic $\mathrm{CH}_{2}-\mathrm{CH}_{3}$ bending, and another peak at $1240.27 \mathrm{~cm}^{-1}$ which was attributed to phenolic compounds in melanin produced by Streptomyces glaucescens NEAE-H [12]. The FTIR spectroscopy results of the extracellular pigment isolated from Xcv (Figure 4) are in agreement with the other previous reports of melanin isolated from microorganisms $[1,10,24,25]$.

Dark brown pigment has been earlier reported in few bacteria and fungus, mostly growing in diverse and extreme environmental conditions viz. from saline water of Lonar lake [26], water samples of saline belt [27], cold, dry and intense ultraviolet radiated area of Antarctic [8], sewage water sample [5], Arabian sea sediments [7]. Melanin pigment can protect microorganisms, such as bacteria and fungi, against thermal as well as chemical and biochemical stresses through the generation of reactive oxygen species [26]. Melanin enhances the survival and competitive abilities of organisms in harsh conditions $[13,14]$. Here in the present study melanin was produced by $X c v$ when exposed to vapour phase (aroma) of aromatic oils, it may be an adaptive response of the bacterium $X c v$ to its surrounding environment.

Melanin is produced predominantly via tyrosinase in many microorganisms where L-tyrosine or L-DOPA is the precursors [12,16,26,27]. Some microorganisms produce melanin without supplementation of tyrosine in media [24], whereas for some microorganism tyrosine has to be incorporated in media [5,26-28]. In Xanthomonas campestris pv. phaseoli, it is formed due to secretion and subsequent oxidation of homogentisic acid [4]. Melanin production is also reported via the activity of laccases, catecholases, poltketide synthase and 4-hydroxyphenylacetic acid hydroxylase enzyme pathways [1-4,6]. In Azotobacter chroococcum active polyphenol oxidase can produce melanin from catechol [2]. In Klebsiella pneumoniae, melanin is produced from 4-hydroxyphenylacetic acid hydroxylase and not tyrosinase [3]. Shrishailnath, et al. [1] also found biosynthesis of melanin from L-tyrosine via 4-hydroxyphenylacetic acid hydroxylase, an unusual pathway of melanogenesis. 4-hydroxyphenylacetic acid hydroxylase catalyzes the hydroxylation of other aromatic compounds, which leads to the formation of dibenzoquinone and other o-quinone derivatives, which then polymerize spontaneously to melanin-like polymers [1,3]. Here in the present study, one of the melanogenesis enzymes in $\mathrm{Xcv}$ may have produced melanin by oxidation of the aromatic compounds of aromatic oil.

Due to the versatile properties of melanin viz. photoprotective, antioxidant (radical scavenging activity), anticancer, antimicrobial, heavy metal scavenger [9$12,17]$, it has been used in a wide range of applications, from cosmetics, pharmaceutical, clinical, agricultural to food industry $[9,29]$. The antimicrobial and antioxidant properties of melanin were demonstrated by Arun, et al. [10], where they reported the antibacterial activity of the extracellular melanin produced by Schizophyllum commune against Escherichia coli, Bacillus subtilis, Klebsiella pneumoniae, and Pseudomonas fluorescens and antifungal activity against Trichophyton simii and T. rubrum at $100 \mu \mathrm{g} /$ $\mathrm{ml}$. They also found that melanin showed high free radical scavenging activity of DPPH (2,2-diphenyl-1-picrylhydrazyl) at $50 \mu \mathrm{g} / \mathrm{ml}$ concentration. Another interesting application of melanin is its photoprotective effect on bioinsecticides. The bioinsecticide made of Bacillus thuringiensis var. israelensis (BTI) is used to controls the growth of mosquito larvae, but its effectivity is greatly affected by UV radiation. The melanin produced from the bacteria Aeromonas media strain WS showed a photoprotective effect on BTI against UV and Sunlight radiation [30]. One more important application of melanin is its use for bioremediation purposes [29], melanin nanoparticles produced by Pseudomonas stutzeri HMGM7 were found to have $-54.9 \mathrm{mV}$ zeta potential, and could efficiently adsorb different heavy metals like lead, chromium, and selenium from drinking water due to their metal affinity and high adsorption ability [17]. Some other applications of melanin include its use in the production/synthesis of nanoparticles, packaging material, microbial fuel cells and sensitized solar cells [29].

The extensive use of melanin has created a huge demand for melanin in the market. The cost of $1 \mathrm{gm}$ of melanin is around $444 \$$ which means it is costlier than the most expensive metal gold [31]. This initiated the need for exploring an environmentally friendly and economically feasible process for melanin production. Scientists have mentioned the possibility of melanin pigment synthesis from microorganisms as an alternative option for commercial production of melanin for industrial use $[1,9,25,29]$. Here in 


\section{Journal of Ecology and Natural Resources}

the present investigation, $4.61 \pm 0.07$ and $5.13 \pm 0.08 \mathrm{mg} / \mathrm{mL}$ melanin was produced by $X c v$ under the effect of firdous and rose aromatic oils, respectively. This is better when compared to earlier reports, for example, Kurian [7] reported the melanin produce of 11 different bacteria isolated from $96 \mathrm{~m}$ depth Arabian sea sediments and it ranged between $27 \mu \mathrm{g} /$ $\mathrm{ml}$ to $504 \mu \mathrm{g} / \mathrm{ml}$ in tyrosine basal broth. While Schizophyllum commune produced $250 \mu \mathrm{g} / \mathrm{l}$ [10], Yarrowia lipolytica NCIM 3590 produced $160 \mathrm{mg} / \mathrm{l}$ [16], Streptomyces glaucescens strain NEAE-H produced $350 \mathrm{mg} / \mathrm{l}$ [12] and Streptomyces sp. produced $2.2 \mathrm{~g} / \mathrm{l}[28]$.

The amount of melanin produced by bacteria is remarkable, but it depends upon various factors. An increase in melanin yield from 163 to $513 \mathrm{mg} / \mathrm{l}$ was reported by Thaira, et al. [17] in Pseudomonas stutzeri strain HMGM-7 after optimization of different parameters like media, carbon and nitrogen source in media, $\mathrm{pH}$ of media, temperature, inoculum load, incubation time. Whereas, Klebsiella sp. GSK produced $130 \mathrm{mg} / \mathrm{l}$ melanin in minimal medium with $\mathrm{L}$-tyrosine, but then the melanin yield increased 4 times to $540 \mathrm{mg} / \mathrm{l}$ when supplemented with $50 \mathrm{mg} / \mathrm{l} \mathrm{L-DOPA}$ along with L -tyrosine [1]. For high production of melanin use of expensive media like Peptone yeast extract iron broth [12], Tryptone soya broth [17], minimal media broth [1], Luria Bertani broth [11] and so on $[10,16,28]$ are used, and most of the time they are supplemented with L- tyrosine $[1,11]$ or LDOPA $[1,16]$ or metal ion [12] to enhance the yield. In order to reduce the production cost Tarangini, et al. [25] used an economical fruit waste extract for melanin production, he successfully optimized the melanin production and obtained $\sim 6.9 \mathrm{mg} / \mathrm{ml}$ melanin yield (at optimum conditions) from a garden soil microbe Bacillus safensis. Here, Nutrient broth was used for melanin production without supplementation of L- tyrosine or L-DOPA which is economical than the other specific media used for melanin production in previous reports. Also, the aromatic oils used here are economic, as they are commercially available synthetic aromatic oils. Thus, microorganisms from different environmental conditions can be tested under the effect of the vapour phase of aromatic oils to identify high melanin yielding microbe.

\section{Conclusion}

To conclude, here we have come across a very different phenomenon i.e. when $\mathrm{Xcv}$ was exposed to vapour phase of specific aromatic oil viz. firdous (Combination of Jasminum officinale, Cinnamomum verum and Nelumbo nucifera) and rose (Rosa damascena), the bacteria produced extracellular dark brown melanin pigment. It is the first report of melanin production by plant pathogenic bacteria XcV and the use of aromatic oils vapour phase (aroma) to produce melanin pigment in bacteria is also novel, thus this technique of melanin production can be further explored for obtaining this costly pigment with minimal cost.

\section{Acknowledgment}

The author would like to thank Department of Plant Pathology and Agricultural Microbiology, Mahatma Phule Krishi Vidyapeeth, Rahuri for providing the required facilities. The first author would like to thank Dr. Mohinder Kadian, International Potato Center (CIP), SWCA, New Delhi to permit the author to do in-service PhD.

\section{References}

1. Shrishailnath S, Kulkarni G, Yaligar V, Kyoung L, Karegoudar TB (2010) Purification and physiochemical charachterization of melanin pigment isolated from Klebsiella sp. GSK. J Microbiol Bitechnol 20(11): 15131520.

2. Shivprasad S, Page WJ (1989) Catechol formation and melanization by $\mathrm{Na}+$-dependent Azotobacter chroococcum: a protective mechanism for aeroadaptation? Appl Environ Microbiol 55(7): 18111817.

3. Gibello A, Ferrer E, Sanz J, Martin M (1995) Polymer production by Klebsiella pneumoniae 4-hydroxyphenylacetic acid hydroxylase genes cloned in Escherichia coli. Appl Environ Microbiol 61(12): 4167 4171.

4. Goodwin PH, Sopher CR (1994) Brown pigmentation of Xanthomonas campestris pv. phaseoli associated with homogentisic acid. Can J Microbiol 40(1): 28-34.

5. Pathan AN, Pethe AS (2016) Studies of melanin producing bacteria and extraction of bacterial melanin from sewage water. Int J Appl Res 2(6): 413-415.

6. Plonka PM, Grabacka M (2006) Melanin synthesis in microorganisms - biotechnological and medical aspects. Acta Biochim Pol 53(3): 429-443.

7. Kurian NK, Nair HP, Bhat SG (2019) Characterization of melanin producing bacteria isolated from $96 \mathrm{~m}$ depth Arabian sea sediments. Res J Biotech 14(3): 64-71.

8. Kimura T, Fukuda W, Sanada T, Imanaka T (2014) Characterization of water soluble dark brown pigment from antarctic bacterium Lysobacter oligtrophicus. J Biosci Bioeng 120(1): 58-61.

9. Tarangini K, Mishra S (2014) Production of melanin by soil microbial isolate on fruit waste extract: two step optimization of key parameters. Biotechnol Rep 4: 139146. 
10. Arun G, Eyini M, Gunasekaran P (2015) Characterization and biological activities of extracellular melanin produced by Schizophyllum commune (Fries). Indian J Exp Biol 53(6): 380-387.

11. Kiran GS, Jackson SA, Priyadarsini S, Dobson ADH, Selvin J (2017) Synthesis of Nm-PHB (nanomelanin polyhydroxy butyrate) nanocomposite film and its protective effect against biofilming multi drug resistant Staphylococcus aureus. Sci Rep 7(1): 9167.

12. El-Naggar NE, El-Ewasy SM (2017) Bioproduction, characterization, anticancer and antioxidant activities of extracellular melanin pigment produced by newly isolated microbial cell factories Streptomyces glaucescens NEAE-H. Sci Rep 7: 42129.

13. Deshmukh KR, Pethe AS (2017) Effect of sunlight on growth and melanin pigment production in bacteria and fungi. Int J Innov Res Sci Eng Technol 6(2): 1668-1670.

14. Eisenman HC, Casadevall A (2012) Synthesis and assembly of fungal melanin. Appl Microbiol Biotechnol 93(3): 931-940.

15. McLean J, Purvis OW, Williamson BJ, Bailay EH (1998) Role for lichen melanins in uranium remediation. Nature 391: 649-650.

16. Apte M, Girme M, Bankar A, Ravikumar A, Zinjarde S (2013) 3, 4-dihydroxy-L-phenylalanine-derived melanin from Yarrowia lipolytica mediates the synthesis of silver and gold nanostructures. J Nanobiotechnol 11: 2.

17. Thaira H, Raval K, Manirethan V, Balakrishnan RM (2019) Melanin nano-pigments for heavy metal remediation from water. Sep Sci Technol 54(2): 265-274.

18. Velazquez-Nunez MJ, Avila-Sosa R, Palou E, Lopez-Malo A (2013) Antifungal activity of orange (Citrus sinensis var. Valencia) peel essential oil applied by direct addition or vapor contact. Food Control 31(1): 1-4.

19. Dorman HJD, Deans SG (2000) Antimicrobial agents from plants: antibacterial activity of plant volatile oils. J Appl Microbiol 88: 308-316.

20. Tyagi AK, Malik A (2011) Antimicrobial potential and chemical composition of Mentha piperita oil in liquid and vapour phase against food spoiling microorganisms. Food Control 22(11): 1707-1714.

21. Nerio LS, Olivero-Verbel J, Stashenko E (2010) Repellent activity of essential oils: A review. Bioresour Technol 101(1): 372-378.

22. West H (2017) What Are Essential Oils, and Do They Work?

23. Borkar SG (2018) Isolation of Bacterial Plant Pathogens 'in' Laboratory techniques in Plant Bacteriology. CRC Press, USA, pp: 35-38.

24. Kumar GC, Sahu N, Reddy GN, Prasad RBN, Nagesh $\mathrm{N}$, et al. (2013) Production of melanin pigment from Pseudomonas stutzeri isolated from red seaweed Hypnea musciformis. Lett Appl Microbiol 57(4): 295-302.

25. Tarangini K, Mishra S (2013) Production, characterization and analysis melanin from isolated marine Pseudomonas $s p$. using vegetable waste. Res J Eng Sci 2(5): 40-46.

26. Deshmukh KR, Pethe AS (2016a) Studies on melanin pigment produced by Phaeosphaeriopsis musae isolated from saline water of lonar lake in west Vidarbha region. Eur J Pharm Med Res 3(9): 347-350.

27. Deshmukh KR, Pethe AS (2016b) Extraction and analysis of melanin pigment produced by Clostridium tertium isolated from water sample of saline belt in west Vidarbha. Int J Sci Res 5(8): 812-814.

28. Deshmukh KR (2012) Isolation, characterization of melanin producing organism and extraction of melanin. Int J Sci Eng Res 3(11): 1-4.

29. Pavan ME, Lopez NI, Pettinari MJ (2020) Melanin biosynthesis in bacteria, regulation and production perspectives. Appl Microbiol Biotechnol 104: 13571370.

30. Wan X, Liu HM, Liao Y, Su Y, Geng J, et al. (2007) Isolation of a novel strain of Aeromonas media producing high levels of DOPA-melanin and assessment of the photoprotective role of the melanin in bioinsecticide applications. J Appl Microbiol 103(6): 2533-2541.

31. Anonymous (2020) Sigma-Aldrich, Product Catalog, Product- Melanin. 